\title{
CHEMICAL MODIFICATION OF POLYMER SURFACE USING 185-nm LIGHT
}

\author{
Masamitsu SHIRAI, Tadateru YATSUO, and Masahiro TSUNOOKA \\ Department of Applied Chemistry, College of Engineering, \\ Osaka Prefecture University, Sakai, Osaka 593, JAPAN
}

Photolithographic processes that use surface imaging techniques have been studied [1]. The predominant approach involves post-exposure silylation of an organic polymer film [2]. Polymer films bearing phenolic - $\mathrm{OH}$ groups are irradiated, followed by selective silylation of the unexposed areas to provide sufficient plasma etch resistance for pattern transfer. In contrast to the silylation process, the selective deposition of metal oxides on the irradiated surface has been studied [3,4]. Recently we have reported a plasma-developable photoresist system based on photoinduced acid-catalyzed polysiloxane formation at irradiated polymer surface bearing photoacid generating moieties by a chemical vapor deposition (CVD) method using alkoxysilane vapor [5]. In this paper we report new photoacid generators sensitive to $185 \mathrm{~nm}$-light and formation of polysiloxanes at the irradiated polymer surface containing those photoacid generators by CVD method using alkoxysilane vapor.

Four types of photoacid generators shown in Scheme 1 were synthesized from acetone oxime or N-hydroxysuccinimide and corresponding sulfonyl chlorides. The procedure for the preparation of $1 \mathbf{a}$ was as follows: To a solution of acetone oxime $(2.0 \mathrm{~g}, 27.4 \mathrm{mmol})$ in pyridine $(22 \mathrm{ml})$ below $5^{\circ} \mathrm{C}$ was slowly added methanesulfonyl chloride $(3.5 \mathrm{~g}, 30.7 \mathrm{mmol})$. The reaction was continued with vigorous stirring at $150 \mathrm{C}$ for $4 \mathrm{hr}$. The reaction mixture was poured into $242 \mathrm{ml}$ of ice-cold $5 \% \mathrm{HCl}$ and extracted with chloroform. After washing the chloroform layer thoroughly with water, the chloroform layer was dried over $\mathrm{K}_{2} \mathrm{CO}_{3}$ and evaporated under reduced pressure. After recrystallization from $n$-heptane, pure product was obtained in $45 \%$ yield. Identification of the compound was done from elemental analysis, 1H-NMR, and FT-IR spectra. 2a was prepared by the same procedure (yield; 33\%). According to the literature [6], 1b and 2b were prepared in 23 and 45\% yield, respectively. Characteristics of the photoacid generators are shown in Table 1. Thermal decomposition temperatures $\left(\mathrm{T}_{\mathrm{d}}\right)$ for $\mathbf{1 b}$ and $\mathbf{2 b}$ were 
higher than those for 1a and 2a. Poly(methyl methacrylate) (PMMA) $\left(M_{n}=107000\right.$, $M_{w} / M_{n}=2.0$ ) was prepared by the conventional radical polymerization of methyl methacrylate. Alkoxysilanes were of reagent grade and used without further purification. Sample films were spin-cast onto glass plates or Si wafers from diglyme solution. Irradiation was carried out at 185 $\mathrm{nm}$ under high vacuum ( $<0.03$ Torr) using low-pressure $\mathrm{Hg}$ lamp.<smiles>[R]OS(C)(=O)=O</smiles><smiles>[R2]OS(C)(=O)=O</smiles><smiles>[R1]CN=C(C)C</smiles><smiles>[R2]CN1C(=O)CCC1=O</smiles>

\section{Scheme 1}

Table 1 Characteristics of photoacid generators

\begin{tabular}{ccccc}
\hline & & & \multicolumn{2}{c}{$\varepsilon(1 / \mathrm{mol} \mathrm{cm}) \mathrm{d})$} \\
\cline { 4 - 5 } Photoacid generatora) & $\left.\mathrm{T}_{\mathrm{m}}\left({ }^{\circ} \mathrm{C}\right) \mathrm{b}\right)$ & $\left.\mathrm{T}_{\mathbf{d}}\left({ }^{\circ} \mathrm{C}\right) \mathrm{c}\right)$ & $193 \mathrm{~nm}$ & $248 \mathrm{~nm}$ \\
\hline $\mathbf{1 a}$ & 46 & 135 & 1900 & 0 \\
$1 \mathbf{b}$ & 154 & 208 & 11500 & 100 \\
$2 \mathbf{2 a}$ & 84 & 139 & 3100 & 10 \\
2b & 91 & 228 & 9800 & 80 \\
\hline
\end{tabular}

a) See Scheme 1. b) Melting point. c) Thermal decomposition temperature from DSC measurement. d) In Acetonitrile.

It has been reported that upon irradiation imino sulfonate compounds form sulfonic acid along with ketone and azine [7]. N-Hydroxyimide sulfonates are known to be photolyzed to form sulfonic acid and imide [8]. Molar extinction coefficients ( $\varepsilon$ ) of $\mathbf{1 b}$ and $2 \mathbf{b}$ at $193 \mathrm{~nm}$ were larger than those of 1a and 2a. All photoacid generators used here showed no significant 
<smiles>[R5]S(=O)(=O)ON=C(C)C</smiles><smiles>[R]PS(=O)(=O)ON1C(=O)CCC1=C[C@H]1CCCC1=O</smiles>

absorption peaks at longer wavelength than $260 \mathrm{~nm}$. Fig. 1 shows the relationship between exposure dose and acid generation. PMMA films (thickness $\sim 1 \mu \mathrm{m}$ ) containing $10 \mathrm{~mol} \%$ of the photoacid generators were irradiated at $185 \mathrm{~nm}$. $1 \mathrm{~b}$ and $2 \mathrm{~b}$ were poorly soluble in PMMA film. The sample film was stripped from the Si wafer with tetrahydrofuran (THF) and added to a stock solution of tetrabromophenol blue mono sodium salt (TBPB) in THF. The amount of acid in the film could be determined by monitoring the absorbance change of the TBPB indicator at $412 \mathrm{~nm}$. The acid generated in the irradiated film increased with exposure dose and reached constant value above $1 \mathrm{~J} / \mathrm{cm}^{2}$. The yield of acid generated from the photoacid generators was $25-40 \%$. The efficiency of acid generation for $1 \mathbf{b}$ and $2 \mathbf{b}$ was slightly higher than that for 1a and $2 a$. The structure of sulfonyl moiety in the photoacid generators did not significantly affect the efficiency of acid generation.

In the presence of water and strong acids such as sulfonic acid, alkoxysilanes can be converted to polysiloxanes. When the irradiated film containing $1 \mathbf{a}, \mathbf{1 b}, \mathbf{2 a}$, or $2 \mathbf{b}$ was exposed to the vapor of $\mathrm{CH}_{3} \mathrm{Si}\left(\mathrm{OC}_{2} \mathrm{H}_{5}\right)_{3}$ at $30^{\circ} \mathrm{C}$, polysiloxanes were formed at the surface region of the films, which was confirmed by FT-IR analysis. The modified films showed new peaks at 3320 (Si-OH), $1270\left(\mathrm{CH}_{3}-\mathrm{Si}\right)$, and $1180-1000 \mathrm{~cm}^{-1}$ (Si-O-Si). Formation of polysiloxane networks by the CVD treatment occurs at air-film interface and beneath the film surface. Relationship between polysiloxane formation and film thickness was studied. The amount of polysiloxanes formed at the irradiated film increased with film thickness and reach a constant value at the thickness above $0.5 \mu \mathrm{m}$, suggesting that the maximum thickness of polysiloxane - PMMA

$$
\mathrm{n} \mathrm{CH}_{3} \mathrm{Si}\left(\mathrm{OC}_{2} \mathrm{H}_{5}\right)_{3}+1.5 \mathrm{n} \mathrm{H}_{2} \mathrm{O} \stackrel{\mathrm{H}^{+}}{\longrightarrow} \text { Polysiloxanes }+3 \mathrm{n}_{2} \mathrm{H}_{5} \mathrm{OH}
$$


composite layer is about $0.5 \mu \mathrm{m}$. Fig. 2 shows polysiloxane formation at the irradiated film surface containing $10 \mathrm{~mol} \%$ of $1 \mathbf{a}$ and $2 \mathbf{a}$. The amount of polysiloxanes formed was estimated from the enhanced absorbance at $1035 \mathrm{~cm}^{-1}$ due to Si-O-Si. $\quad 2 a$ was more effective for the formation of polysiloxanes than 1a. The amount of acid formed photochemically in the film was almost the same for $1 \mathbf{a}$ and $2 \mathbf{a}$. Since methanesulfonic acid generated in the film by the photolysis of $1 \mathrm{a}$ is liquid at ambient temperature, it may move to the film surface, causing a rapid formation of polysiloxane networks at very top surface. This prevents the diffusion of alkoxysilane vapor into the film.

\section{References}

1. L. F. Thompson, C. G. Willson, M. J. Bowden, "Introduction to Microlithography", American Chemical Society (1994) p. 239.

2. F. Coopmans, B. Roland, Proc. SPIE, 631 (1986) 34.

3. G. N. Taylor, L. E. Stillwagon, T. Venkatesan, J. Electrochem. Soc., 131 (1984) 1658.

4. D. Nalamasu, G. N. Taylor, Proc. SPIE, 1086 (1989) 186.

5. M. Shirai, M. Tsunooka, Proc. 10th International Conference on Photopolymers, New York, Mid-Hudson Section, SPE, Ellenville, New York (1994) p.128.

6. C. A. Renner, U.S. Patent 4,371,605 (1983).

7. M. Shirai, H. Kinoshita, M. Tsunooka, Eur. Polym. J., 28 (1992) 379.

8. J. I. G. Cadogan, A. G. Rowley, J. Chem. Soc. Perkin I, (1975) 1069.

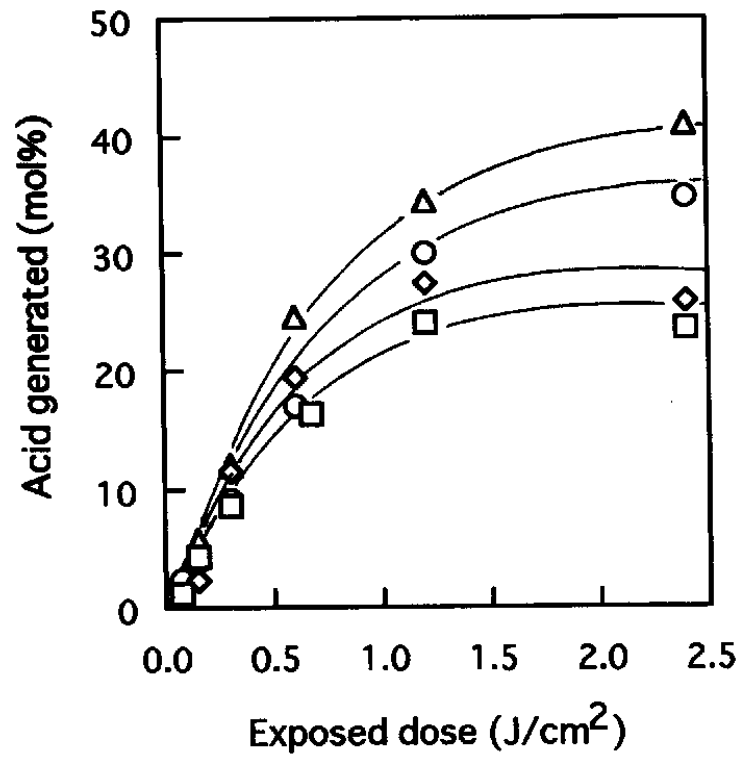

Figure 1. Photoinduced generation of acid from $1 \mathbf{a}(\square), \mathbf{1 b}(\bigcirc), \mathbf{2 a}(\diamond)$, and $\mathbf{2 b}(\triangle)$ in PMMA film.

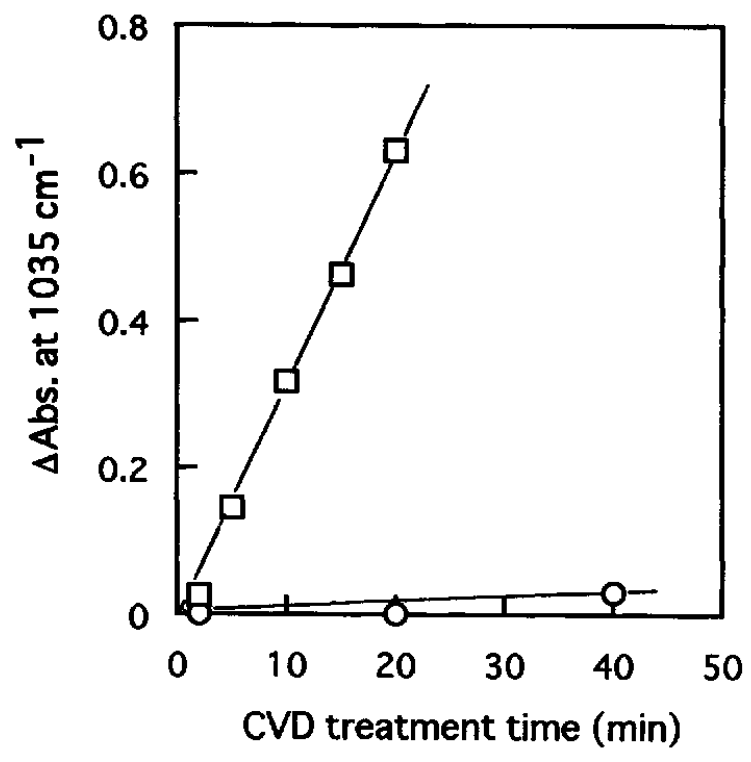

Figure 2. Polysiloxane formation at the irradiated film surface containing 10 mol\% of $1 \mathrm{a}(\bigcirc)$ and $2 \mathrm{a}$ ( $\square$ ). Exposed dose; $600 \mathrm{~mJ} / \mathrm{cm}^{2}$. 